\title{
An Efficient Synthesis of Alkynyl Selenides and Telurides from Terminal Acetylenes and Diorganoyl Dichalcogenides Catalyzed by Copper Oxide Nanopowder Marcelo Godoi ${ }^{1}$ (PG) ${ }^{*}$, Eduardo Wronscki Ricardo ${ }^{1}$ (IC), Tiago Elias Frizon ${ }^{1}$ (PG), Devender Singh $^{2}(\mathrm{PG})$ and Antonio Luiz Braga ${ }^{1}(\mathrm{PQ})$
}

\author{
${ }^{1}$ Universidade Federal de Santa Catarina \\ ${ }^{2}$ Universidade Federal de Santa Maria \\ *cabeloqmc@gmail.com
}

Keywords: alkynyl chalcogenides, copper oxide nanopowder, acetylene

\section{INTRODUCTION}

Alkynyl chalcogenides are interesting class of compounds having a variety of uses in organic synthesis. Especially, alkynylselenides and alkynyl telurides have been used as useful precursors in hydroamination, hydrosulfonation and hydroboration reactions. ${ }^{1}$

The most commonly method used for the synthesis of alkynyl calcogenides involves metal-assisted cross coupling reaction by using either $\mathrm{Mg}$ or $\mathrm{Cu}$ salts. ${ }^{2}$ However, delicate reaction conditions or stoichiometric amount of metal salts were the main drawbacks for these protocols.

On the other hand, $\mathrm{CuO}$ nanopowder has emerged as a useful catalyst in several transformations, and it has also been employed with success in the synthesis of organochalcogenides. ${ }^{3}$

Thus, according to our ongoing research into organochalcogen chemistry, herein we have reported the synthesis of the alkynyl selenides and telurides by using $\mathrm{CuO}$ nanopowder as catalyst.

\section{RESULTS AND DISCUSSION}

In order to optimize the best reaction conditions we used phenylacetylene and diphenyl diselenide as starting materials to afford the desired product. At first, we evaluated the amount of $\mathrm{CuO}$ nanopowder as well as the temperature and time (Scheme 1).

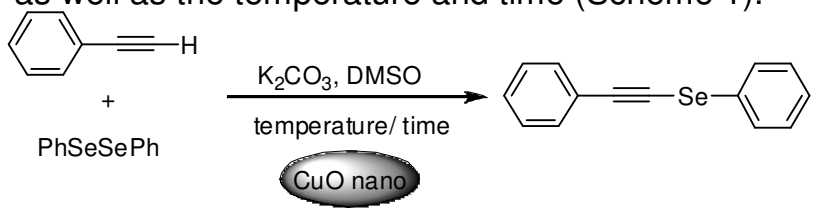

Scheme 1. Optimization for the reaction

Therefore, the best results were achieved by carrying out the reaction at $80{ }^{\circ} \mathrm{C}$, with $10 \mathrm{~mol} \%$ of $\mathrm{CuO}$ nano for $14 \mathrm{~h}$. After the initial studies, we then evaluated the influence of differents bases and solvents on the reaction (Table 1 ). It is noteworthy that the best reaction condition was established by using DMSO as solvent and $\mathrm{K}_{2} \mathrm{CO}_{3}$ as base (entry 1).
Table 1. Optimization of the base and solvent

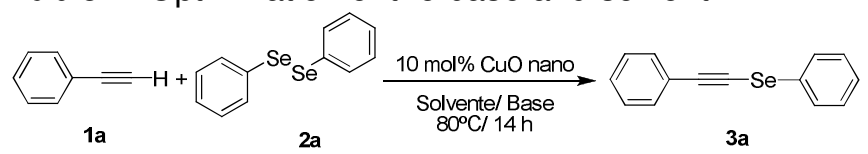

\begin{tabular}{lccc}
\hline$\#$ & Base & Solvent & Yield(\%) \\
\hline 1 & $\mathrm{~K}_{2} \mathrm{CO}_{3}$ & DMSO & 80 \\
2 & $\mathrm{~K}_{2} \mathrm{CO}_{3}$ & DMF & 69 \\
3 & $\mathrm{~K}_{2} \mathrm{CO}_{3}$ & $\mathrm{CH}_{3} \mathrm{CN}$ & 51 \\
4 & $\mathrm{KOH}$ & $\mathrm{DMSO}$ & 32 \\
5 & $\mathrm{Na}_{2} \mathrm{CO}_{3}$ & DMSO & 65 \\
6 & - & DMSO & traces \\
\hline${ }^{a}$ Isolated yields. & &
\end{tabular}

With the best conditions in hand, we then examined the scope of our system, by reacting several acetylenes with different diorganoyl dichalcogenides. As depicted in Scheme 2, the desired products were obtained from moderate to excellent yield.

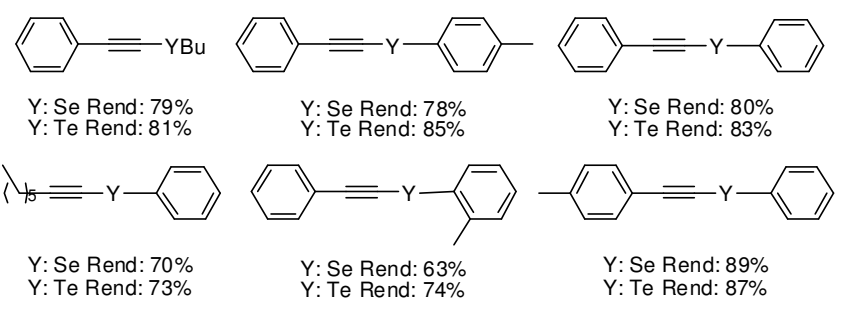

Scheme 2. Alkynyl chalcogenides synthesized

\section{CONCLUSION}

In summary, we have successfully developed an efficient and handle methodology to obtain alkynyl selenides and telurides from acetylenes and diorganoyl dichalcogenides, using $\mathrm{CuO}$ nanopowder as a recyclable catalyst.

\section{ACKNOWLEDGEMENTS}

CAPES, FAPESC, CNPq (INCT-Catálise), UFSC.

\section{REFERENCES}

(a) Comasseto, J. V. J. Organomet. Chem. 1983, 253, 131. (b) Braga, A L.; Reckziegel, A.; Silveira, C. C.; Comasseto, J. V. Synth. Commun. 1994 24, 1165. (c) Comasseto, J. V.; Menezes, P. H.; Stefani, H. A.; Zeni, G.; Braga, A. L. Tetrahedron 1996, 52, 9687.

${ }^{2}$ (a) Das, J. P.; Roy, U. K.; Roy, S. Organometallics 2005, 24, 6136; (b)

Braga, A. L. et al. Tetrahedron Lett. 1993, 34, 393.

${ }^{3}$ Singh, D.; Narayanaperumal, S.; Gul, K.; Godoi, M.; Rodrigues, O. E. D.;

Braga, A. L. Green Chem. 2010, 12, 957. 